\title{
Lipid Profile of Activated Macrophages and Contribution of Group V Phospholipase $A_{2}$
}

\author{
Masaya Koganesawa, Munehiro Yamaguchi, Sachin K. Samuchiwal and Barbara Balestrieri *(D) \\ Department of Medicine, Division of Allergy and Clinical Immunology, Brigham and Women's Hospital, \\ Harvard Medical School, Boston, MA 02115, USA; mkoganesawa@bwh.harvard.edu (M.K.); \\ munehiro1006@yahoo.com (M.Y.); ssamuchiwal@bwh.harvard.edu (S.K.S.) \\ * Correspondence: bbalestrieri@bwh.harvard.edu
}

Citation: Koganesawa, M.; Yamaguchi, M.; Samuchiwal, S.K.; Balestrieri, B. Lipid Profile of Activated Macrophages and Contribution of Group V Phospholipase $\mathrm{A}_{2}$. Biomolecules 2021, 11, 25. https://doi.org/biom 11010025

Received: 30 November 2020 Accepted: 23 December 2020 Published: 29 December 2020

Publisher's Note: MDPI stays neutral with regard to jurisdictional claims in published maps and institutional affiliations.

Copyright: () 2020 by the authors. Licensee MDPI, Basel, Switzerland. This article is an open access article distributed under the terms and conditions of the Creative Commons Attribution (CC BY) license (https: / / creativecommons.org/ licenses/by/4.0/).

\begin{abstract}
Macrophages activated by Interleukin (IL)-4 (M2) or LPS+ Interferon (IFN) $\gamma$ (M1) perform specific functions respectively in type 2 inflammation and killing of pathogens. Group V phospholipase $\mathrm{A}_{2}$ (Pla2g5) is required for the development and functions of IL-4-activated macrophages and phagocytosis of pathogens. Pla2g5-generated bioactive lipids, including lysophospholipids (LysoPLs), fatty acids (FAs), and eicosanoids, have a role in many diseases. However, little is known about their production by differentially activated macrophages. We performed an unbiased mass-spectrometry analysis of phospholipids (PLs), LysoPLs, FAs, and eicosanoids produced by Wild Type (WT) and Pla2g5-null IL-4-activated bone marrow-derived macrophages (IL-4)BM-Macs (M2) and (LPS+IFN $\gamma$ )BM-Macs (M1). Phosphatidylcholine (PC) was preferentially metabolized in (LPS+IFN $\gamma$ )BM-Macs and Phosphatidylethanolamine (PE) in (IL-4)BM-Macs, with Pla2g5 contributing mostly to metabolization of selected PE molecules. While Pla2g5 produced palmitic acid (PA) in (LPS+IFN $\gamma$ )BM-Macs, the absence of Pla2g5 increased myristic acid (MA) in (IL-4)BM-Macs. Among eicosanoids, Prostaglandin $\mathrm{E}_{2}\left(\mathrm{PGE}_{2}\right)$ and prostaglandin $\mathrm{D}_{2}\left(\mathrm{PGD}_{2}\right)$ were significantly reduced in (IL-4)BM-Macs and (LPS+IFN $\gamma$ )BM-Macs lacking Pla2g5. Instead, the IL-4-induced increase in 20-carboxy arachidonic acid (20 CooH AA) was dependent on Pla2g5, as was the production of 12-hydroxy-heptadecatrienoic acid (12-HHTrE) in (LPS+IFN $\gamma$ )BM-Macs. Thus, Pla2g5 contributes to $\mathrm{PE}$ metabolization, $\mathrm{PGE}_{2}$ and $\mathrm{PGD}_{2}$ production independently of the type of activation, while in (IL-4)BM-Macs, Pla2g5 regulates selective lipid pathways and likely novel functions.
\end{abstract}

Keywords: Group V phospholipase $\mathrm{A}_{2}$; macrophages; lipids

\section{Introduction}

Macrophages are heterogeneous cells that contribute to the pathogenesis of infectious disease, type 2 immune responses, and metabolic disorders [1-3]. Macrophages exposed to pathogen-associated molecular patterns (PAMPS), endogenously formed danger-associated molecular patterns (DAMPs), and to the microenvironmental milieu rearrange their repertoire of cytokines and chemokines and contribute to the immune responses [4,5]. In vitro, the immune responses of macrophages are simplified by LPS+Interferon (IFN) $\gamma$ (M1) and Interleukin (IL)-4 (M2) polarization [6,7]. Although it is unlikely that macrophages in vivo exist in mutually exclusive phenotypes $[2,4]$, the polarization paradigm has helped to dissect critical immune features of macrophages. M2 macrophages develop during type 2 inflammation, prompted by Type 2 cytokines including IL- 4 and IL-13, and they are characterized by the production of CCL22, CCL17, Arginase-1, and Transglutaminase 2 (TGM2) [7-9]. M1 macrophages develop during infection and are equipped with an array of cytokines, including IL-12, TNF $\alpha$, and reactive oxygen species (ROS), to fight pathogens. Metabolically, macrophage polarization is distinguished by activation of aerobic glycolysis in M1 macrophages, particularly when M1 activation is achieved by IFN $\gamma$, in addition to LPS [10] and fatty acid oxidation in M2 [11]. Fatty acids (FAs) are involved in the remodeling of membrane phospholipid (mPLs), macrophage development and polarization [12-14], 
and they are essential for phagocytosis by fully differentiated macrophages [14]. Furthermore, polyunsaturated fatty acids (PUFAs) are the precursors of eicosanoids, proor anti-inflammatory lipid mediators, which are generated through three main pathways, cyclooxygenase (COX), lipoxygenase (LOX), and monooxygenases like CYP450 (CYP). Even before the identification of macrophage polarization and their spectrum of phenotypes, stimuli like Granulocyte macrophage colony-stimulating factor (GM-CSF) and IL-4 reportedly induced 5-lipoxygenase (5-LOX) activation in macrophages [15,16], the limiting step in the generation of Cysteinyl leukotrienes (CysLTs), major mediators of inflammation [17]. COX-derived Prostaglandin $\mathrm{E}_{2}\left(\mathrm{PGE}_{2}\right)$ and $\mathrm{PGD}_{2}$ may have proor anti-inflammatory functions associated with LPS or IL-4 immune responses [18-20]. CYP2J2-derived epoxyeicosatrienoic acids (EETs) have opposite roles in human monocytemacrophages depending on the activation state of the macrophages [21], while CYP omegaoxidase 20-hydroxy-eicosatetraenoic acid (20-HETE) and its metabolite 20-carboxy arachidonic acid (20 CooH AA) may have anti-inflammatory properties due to the ability to activate Peroxisome Proliferator-Activated Receptor $\alpha$ (PPAR $\alpha)$ and PPAR $\gamma$ [22] while also activating G Protein-Coupled Receptor 75 (GPR75) [23]. However, whether M1 or M2 activated macrophages differentially produce FAs and eicosanoids has not been fully elucidated, but is potentially critical to understand how lipids produced by macrophages may contribute alone or in combination to the many diseases involving activated macrophages.

The release of FAs and eicosanoids requires the activity of at least one of the phospholipases $\mathrm{A}_{2}\left(\mathrm{PLA}_{2} \mathrm{~s}\right)$ enzymes. $\mathrm{PLA}_{2} \mathrm{~s}$ hydrolyze membrane phospholipids to generate FAs, including saturated fatty acids, monounsaturated fatty acids (MUFAs), and polyunsaturated fatty acids (PUFAs) and their metabolites eicosanoids, and lysophospholipids (LysoPLs). As PLA $\mathrm{P}_{2}$ have substrate specificities and cell-expression preferences, likely, activated macrophages would preferentially express one or more $\mathrm{PLA}_{2} \mathrm{~S}$ and, thus, contribute to the generation of selective bioactive lipids. It is worth noting that the constitutive and ubiquitous group IVA cytosolic PLA $\mathrm{P}_{2}$ ( $\mathrm{CPLA}_{2} \alpha$ or Pla2g4a), which preferentially releases Arachidonic Acid (AA), is expressed more abundantly in M1 macrophages than in M2 macrophages [24]. Of the secretory PLA $_{2}$ family members, group V PLA 2 (Pla2g5) is expressed in macrophages [25] and other cells [26]. Several studies, including ours, have reported the presence of Pla2g $5 \mathrm{mRNA}$ and protein in bone marrow-derived macrophages (BM-Macs), peritoneal macrophages, human monocyte-derived macrophages, macrophagecell lines [27]. Pla2g5 can potentiate Pla2g4a activation and AA release in macrophages activated with Toll-Like Receptor (TLR) agonists [28] and is required for phagocytosis and killing of pathogens $[27,29]$. In vivo, its absence results in increased LPS inflammation and mortality following Candida infection $[30,31]$. On the other hand, Pla2g5 is induced by IL-4 in mouse and human macrophages [20,32-34] and is expressed together with TGM2 in macrophages present in human nasal polyps of subjects with chronic rhinosinusitis [20]. Furthermore, Pla2g5 contributes to M2 macrophage development and functions [20,33,34]. Indeed, in allergic type 2 inflammation, Pla2g5 potentiates inflammation and activation of target cells, including T-cells and innate lymphoid cells type 2 (ILC2s) through the generation of the linoleic acid (LA) and oleic acid (OA) [32,34]. However, the contribution of Pla2g5 to lipid generated during M1 and M2 polarization is still not known, but is potentially critical to account for the functions of M1 and M2 macrophages.

To investigate the lipid generated during macrophage polarization, we activated BM-Macs with IL-4 or LPS+IFN $\gamma$ and analyzed FAs, PLs, LysoPLs, and eicosanoids by gas chromatography coupled to mass spectrometry (GC-MS) and liquid chromatography coupled to mass spectrometry (LC-MS). We found that macrophages activated by LPS+IFN $\gamma$ or IL-4 rearrange their membrane phospholipid composition by decreasing phospholipid content, particularly Phosphatidylethanolamines (PE) during IL-4 activation and Phosphatidylcholine (PC) during LPS+IFN $\gamma$ activation. Furthermore, in M2 macrophages, the absence of Pla2g5 increased PE 34:2, PE 36:2, PE 38:4, and PE 38:5, while in M1 macrophages, there was a significant increase in PC 34:1 and PC 36:2. LysoPLs were not significantly modified during macrophage activation in BM-Macs lacking Pla2g5. We 
also found that Pla2g5 regulated the release of selective saturated fatty acids in activated BM-Macs. Furthermore, $\mathrm{PGD}_{2}$ and $\mathrm{PGE}_{2}$ were significantly induced by Pla2g5 in both M1 and M2 activation, while 20CooH AA production was dependent on Pla2g5 only in M2. Therefore, it is likely that the combined action of the lipids produced by M1 and M2 macrophages may contribute to the functions of macrophages in different settings. Identifying potential lipid signatures in M1 and M2 macrophages could uncover new pathways critical for the development, persistence, or reduction of inflammation. Some of these functions may rely on the presence or absence of Pla2g5 in macrophages.

\section{Materials and Methods}

\subsection{Macrophage Cultures}

BM-Macs were generated as previously described [34]. Briefly, BM cells were collected from femurs and tibiae of mice of Wild Type (WT) and Pla2g5-null mice [35]. The disaggregated cells were counted and suspended in complete medium (Dulbecco's Modified Eagle Medium (DMEM) F12, 5\% Fetal Bovine Serum (FBS), $100 \mathrm{U} \mathrm{mL}^{-1}$ penicillin, $100 \mathrm{mg} \mathrm{mL}^{-1}$ streptomycin, $0.1 \mathrm{mM}$ nonessential amino acids, $2 \mathrm{mM}$ L-glutamine and $0.05 \mathrm{mM}$ 2-mercaptoethanol (2-ME)) at a concentration of $4.0 \times 10^{6}$ cells per $\mathrm{mL}$ in $10 \mathrm{~mL}$ in $100 \mathrm{~mm}$ Petri dish. WT and Pla2g5-null BM-macrophages were cultured for 7 days in $50 \mathrm{ng} \mathrm{mL}{ }^{-1}$ murine recombinant-Macrophage Stimulating Factor (rM-CSF) (PeproTech). Macrophages were activated with IL-4 or LPS+IFN $\gamma$ (PeproTech) for $24 \mathrm{~h}$, as previously described [32]. Supernatants and adherent cells were collected [20,34], frozen, and shipped for analysis by mass spectrometry.

Human monocyte-derived macrophages were generated as previously described [20]. Briefly, leukocyte-enriched buffy coat from healthy donors was overlaid on Ficoll-Paque Plus (GE Healthcare, Buckinghamshire, UK) and centrifuged at $600 \times g$ for $20 \mathrm{~min}$. The mononuclear layer at the interface was collected, washed, and counted. Monocytes were isolated by negative selection (Miltenyi Biotec, Auburn, CA, USA) and plated at $2.2 \times 10^{5}$ cells $/ \mathrm{cm}^{2}$ in $100 \mathrm{~mm}$ Petri dishes. Monocytes were cultured for $13 \mathrm{~d}$ in complete medium (RPMI 1640, 10\% FBS, 2 mM L-glutamine, $100 \mathrm{U} / \mathrm{mL}$ penicillin, $100 \mathrm{mg} / \mathrm{mL}$ streptavidin, 10\% nonessential amino acids, 1\% 4-(2-hydroxyethyl)-1-piperazineethanesulfonic acid (HEPES), 1\% sodium pyruvate, and $50 \mathrm{mM}$ 2-ME supplemented with $50 \mathrm{ng} \mathrm{mL}^{-1}$ human rGM-CSF (R\&D Systems, Minneapolis, MN, USA) [36]. To knock down PLA2G5, monocytes were cultured for $13 \mathrm{~d}$ in rGM-CSF, then they were transfected with human PLA2G5 ON-TARGET Plus SMART Pool siRNA or nontargeting vector ONTARGET Plus Control Pool (1000 nM; GE Dharmacon, Lafayette, CO, USA) as previously described [20]. To activate macrophages, cells were polarized for $24 \mathrm{~h}$ in complete medium, supplemented with $40 \mathrm{ng} \mathrm{mL}^{-1}$ human IL-4 (R\&D Systems). Cell-free supernatants were collected, frozen and shipped for analysis by mass spectrometry.

\subsection{Mass Spectrometry of Lipids}

Lipid analysis was performed at the University of California San Diego Lipidomics Core [37]. For analysis of eicosanoids samples, the amount of sample used was $200 \mu \mathrm{L}$, and $100 \mu \mathrm{L}$ internal standard was added. Lipids were extracted with Solid Phase Extraction (SPE): Strata-x polymeric reverse phase columns (8B-S100-UBJ; Phenomenex, Torrance, CA, USA). The following was added to each column: 100\% $\mathrm{MeOH}, 100 \% \mathrm{H}_{2} \mathrm{O}$, sample, $10 \%$ $\mathrm{MeOH}$, and $100 \% \mathrm{MeOH}$ for elution. Samples were dried with a Speed-Vac (Thermo Scientific) and taken up in $100 \mathrm{~mL}$ buffer $\mathrm{A}\left(63 \% \mathrm{H}_{2} \mathrm{O}, 37 \%\right.$ acetonitrile, $0.02 \%$ acetic acid). Five microliters were injected into the ultra-high performance liquid chromatography system. The analysis was performed with a mass spectrometer (6500 Qtrap; Sciex, Framingham, MA, USA) [38]. For analysis of phospholipids, samples were extracted via Bleigh Dyer. Samples were dried down and taken up in $50 \mu \mathrm{L}$ buffer A (59/40/1 isopropanol (IPA)/hexane (HEX)/ $\mathrm{H}_{2} \mathrm{O}$ with $10 \mathrm{mM} \mathrm{NH}{ }_{4} \mathrm{OAC}$ ). Then, $10 \mu \mathrm{L}$ were injected into UPLCMS/MS. The first number of the phospholipids designates the total number of carbons and the second number after the colon indicates the total number of double bonds. For 
example, PC 36:4 indicates a phospholipid molecule with a total of 36 carbons and 4 double bonds. Lysophosphatidylcholine (LysoPC)-O and PC-O indicate ether-linked fatty acids in the sn-1 position. We measure isobaric species. For example, PC 36:4 can consist of either PC (18:2; 18:2) or PC (16:0; 20:4). Similarly, we did not discriminate between 34:0 PC and 36:7 PC-O_both have identical molecular masses and are not separated by LC-MS.

FA analysis was performed according to a previously published method [39]. Briefly, the cell pellet was homogenized in $500 \mathrm{~mL}$ of PBS/10\% methanol. An aliquot of $200 \mathrm{~mL}$ corresponding to about $0.5 \times 10^{6}$ cells was withdrawn and a cocktail of internal standards consisting of 15 deuterated fatty acids was added. The extraction was initiated with $500 \mathrm{~mL}$ of methanol and $25 \mathrm{~mL}$ of $1 \mathrm{~N} \mathrm{HCl}$ and a bi-phasic solution is formed by addition of $1.5 \mathrm{~mL}$ of isooctane. The phases are separated by centrifugation and the isooctane phase containing the FFAs fraction was removed. The extraction is repeated once and the combined extracts were evaporated to dryness. The FFAs were derivatized with pentafluorobenzyl (PFB) bromide and the resulting fatty acid PFB esters were analyzed by gas chromatography/mass spectrometry using a negative chemical ionization mode (Agilent 6890N gas chromatograph equipped with an Agilent 5973 mass selective detector; Agilent, Santa Clara, CA, USA). Standard curves for each of the fatty acids were acquired in parallel using identical conditions. The quantitative assessment of fatty acids in a sample was achieved by comparison of the mass spectrometric ion signal of the target molecule normalized to the internal standard with the matching standard curve according to the isotope dilution method and by protein content.

\section{3. $q P C R$}

Total RNA was isolated from lysate with the RNeasy Micro Kit (Qiagen, Louisville, KY, USA), reverse transcribed into cDNA (High-Capacity cDNA Reverse Transcription Kit; Thermo ARTICLES science-Applied Biosystems, Foster City, CA, USA) and measured by real-time PCR with the use of SYBR ${ }^{\circledR}$ Green/ROX master mix (SABiosciences, Frederick, MD, USA) on an Mx3005P thermal cycler (Stratagene, Santa Clara, CA, USA). The ratio of each mRNA relative to the Glyceraldehyde-3-Phosphate Dehydrogenase (GAPDH) mRNA was calculated with the $\Delta \Delta \mathrm{Ct}$ threshold cycle method. The mouse primers used were GAPDH F: 5'-TCAACAGCAACTCCCACTCTTCCA-3'; R: 5'-ACCCTGTTGCTGTAGCCGT ATTCA-30' Pla2g5 F: 5'-TGGTTCCTGGCTTGCAGTGTG-3'; R: 5'-TTCGCAGATGACTAGG CCATT-3' [34]. Real-time PCR products were run on a $1.5 \%$ agarose gel and visualized using chemilmager 4400 fluorescence system (Alpha Innotech, Missouri, TX, USA).

\subsection{Statistical Analysis}

Comparisons between two groups were made by using an unpaired Student's $t$ test, and other comparisons were made with two-way ANOVA with Tukey, Sidak, or Dunnett correction for multiple comparisons. Comparisons were performed with Prism software (GraphPad, San Diego, CA, USA). Data are expressed as mean \pm standard error of the mean (SEM); significance was set at $p<0.05$.

\section{Results}

3.1. Phospholipid Metabolism in Bone Marrow-Derived Macrophages Activated by IL-4 or $L P S+I F N \gamma$

To investigate the production of bioactive lipids in activated BM-Macs, we first asked whether, during macrophage activation, there were changes in the composition of membrane phospholipids (PLs), substrates of PLA 2 . We cultured mouse BM-Macs for 7 days in rM-CSF and $24 \mathrm{~h}$ with IL-4 or LPS+IFN $\gamma$, hereafter referred to as (IL-4)BM-Macs or (LPS+IFN $\gamma$ )BM-Macs, respectively, for M2 or M1 (Figure 1a, inset), to distinguish them from other in vitro derived M2 or M1 macrophages [40]. The supernatants were collected and the phospholipid species analyzed by mass spectrometry. Five PL species were detected in resting WT BM-Macs. Phosphatidylcholine (PC) was the most abundant, followed by phosphatidylethanolamines (PE), while phosphatidylinositol (PI), phos- 
phatidylserine (PS), and phosphatidic acid (PA) contributed minimally to membrane composition (Figure 1a, black columns). Compared to WT unstimulated (U)BM-Macs, PE was significantly decreased in WT (IL-4)BM-Macs, while PC was significantly reduced in (LPS+IFN $\gamma$ )BM-Macs (Figure 1a). PC, PS, PI, and PA did not change following activation. PG species were undetectable. These data suggest that PE could be the prevalent substrate for a PLA 2 in (IL-4)BM-Macs and PC in (LPS+IFN $\gamma$ )BM-Macs, although other phospholipases could contribute to remodeling of membrane phospholipids.

(a)
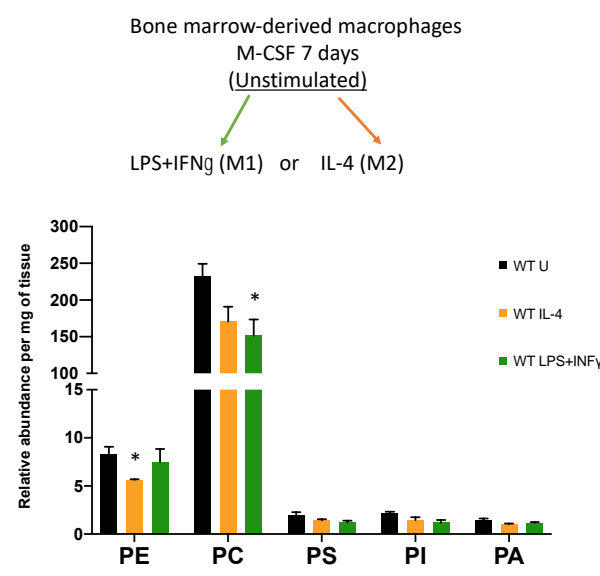

(c)

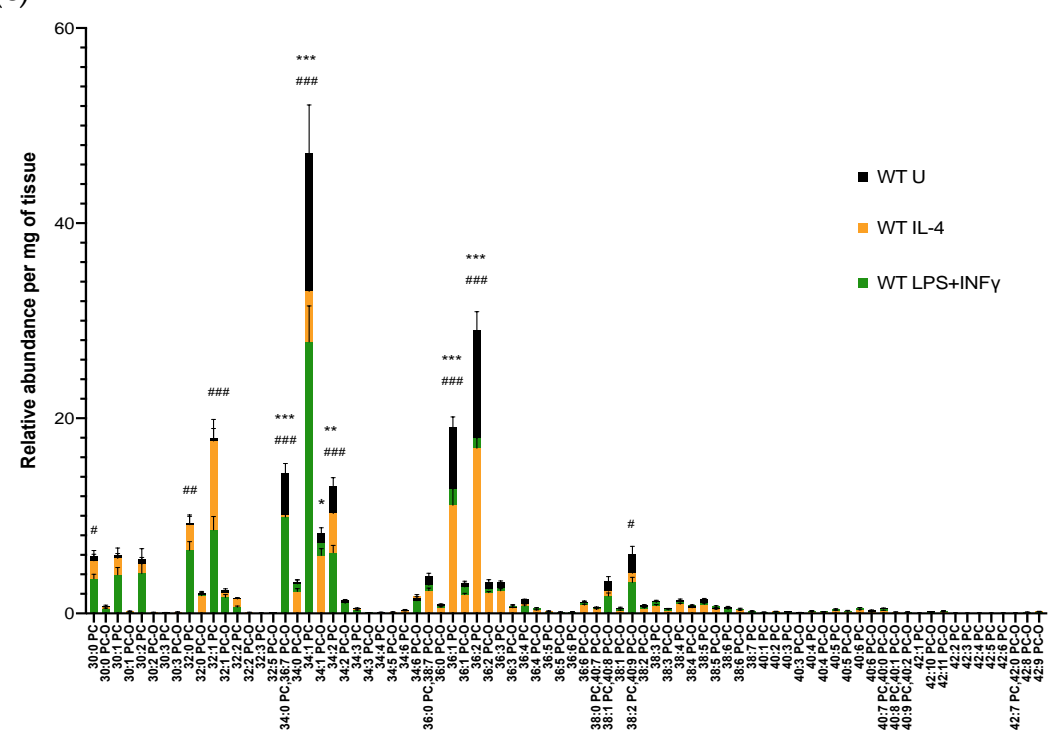

(b)

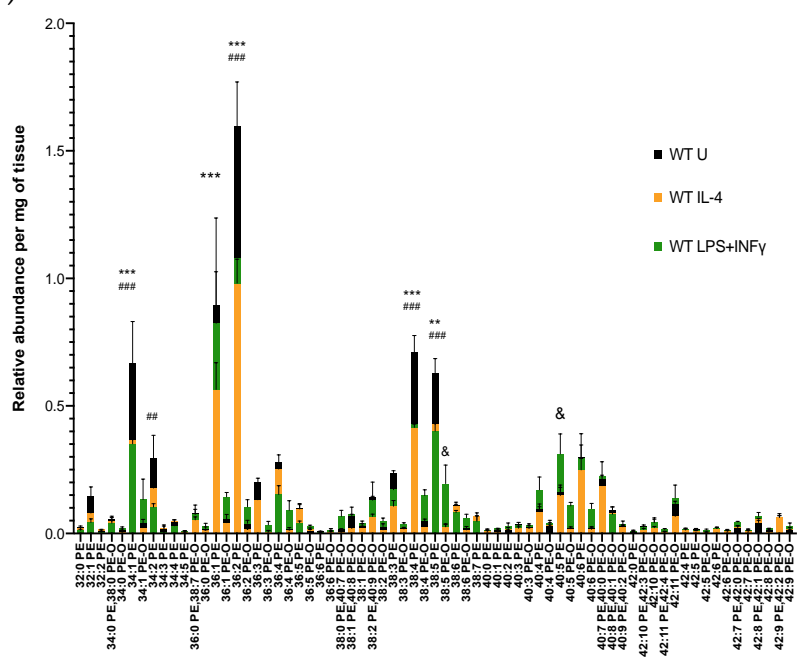

(d)

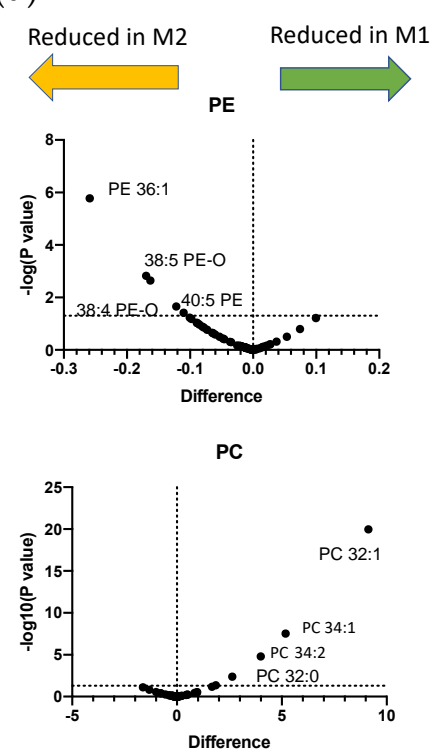

Figure 1. Phospholipid metabolism in bone marrow-derived macrophages (BM-Macs). Wild Type (WT) BM-Macs were Unstimulated (U) or stimulated with Interleukin (IL)-4 or LPS+ Interferon (IFN) $\gamma$ for $24 \mathrm{~h}$, supernatants were removed and collected for analysis by liquid chromatography coupled to mass spectrometry (LC-MS). (a) ${ }^{*} p<0.05$ of (U) vs. IL-4 or LPS+IFN $\gamma$ BM-Macs. (b,d) Phosphatidylethanolamine (PE) molecules or (c,d) phosphatidylcholine (PC) molecules are identified by the binding of fatty acids which are described by the numbers of carbons and double bonds. PE-O and PC-O indicate ether linked fatty acids in the sn-1 position. The data are shown volcano plot of mean (d) or graph (a-c) of mean and standard error of three independent determinations. ${ }^{* * *} p<0.0001,{ }^{* *} p<0.005$ (IL-4)BM-Macs reduction vs (U)BM-Macs; \#\#\# $p<0.0001, \# p<0.005,{ }^{*} p<0.05$ (LPS+IFN $\gamma$ )BM-Macs reduction vs. (U)BM-Macs; \& $p<0.05$ increase in (LPS+IFN $\gamma$ )BM-Macs vs. (U)BM-Macs. $p$-values were obtained by two-way ANOVA with Dunnett's correction for multiple comparisons. 
Next, we wanted to ascertain whether, among PE or PC species, there were preferred phospholipid molecules decreased during each of the macrophage activation models and, therefore, preferred bioactive lipid produced. We analyzed 69 PE molecules. In WT (U)BM-Macs, PE 36:2 was the most abundant. Compared to WT (U)BM-Macs, PE 34:1, PE 36:2, PE 38:4, and PE 38:5 were significantly decreased in both (IL-4) and $($ LPS+IFN $\gamma$ )BM-Macs, and PE 34:2 was significantly reduced in (LPS+IFN $\gamma$ )BM-Macs while PE 36:1 was significantly reduced in (IL-4)BM-Macs (Figure 1b). These data indicate that long-chain PUFAs, including AA, are liberated from PE in both IL-4 and LPS+IFN $\gamma$ activation. Instead, PE-O 38:5 and PE 40:5 were significantly increased in WT (LPS+IFN $\gamma$ )BM-Macs compared to WT (U)BM-Macs, likely indicating re-acylation. Of the 80 PC species analyzed (Figure 1c), PC 34:1 was the most abundant in WT (U)BM-Macs and was reduced in both (IL-4) and (LPS+IFN $\gamma$ )BM-Macs as were PC 34:2, PC 36:1, PC 36:2 PC-O 34:0/PC-O 36:7. LPS+IFN $\gamma$ activation resulted in the selective reduction of PC 30:0, PC 32:0, PC 32:1, and PC 38:2/PC-O 40:9 compared to (U)BM-Macs. A direct comparison of PE or PC molecules in (IL-4)BM-Macs versus (LPS+IFN $\gamma$ )BM-Macs confirmed that PE species were preferentially reduced and likely metabolized in (IL-4)BM-Macs and PC species in (LPS+IFN $\gamma$ )BM-Macs (Figure 1d). These results suggest that one or more $\mathrm{PLA}_{2}$ may hydrolyze preferred substrates in IL-4 or LPS+IFN $\gamma$ activated macrophages.

Since Pla2g5 is induced by IL-4 [32,34] and prefers PE as a substrate at least in human monocyte-macrophages activated by IL-4 [33], we wanted to understand whether the changes in membrane phospholipid were due at least partially to Pla2g5, particularly in IL-4 BM-Macs. We confirmed that Pla2g5 is induced in mouse BM-Macs by IL-4, but not LPS+IFN $\gamma$ (Figure 2a) as previously shown [32]. In Pla2g5-null BM-Macs, PE was significantly increased in unstimulated, IL-4 and LPS+IFN $\gamma$ stimulated BM-Macs compared to equally treated WT BM-Macs (Figure 2b) while PC was similar in both WT and Pla2g5null BM-Macs independently of the activation state. Furthermore, compared to equally treated WT BM-Macs, the percentage increase of PE was $71.7 \pm 21.1 \%$ in (IL-4)BM-Macs, $41.1 \pm 2.4 \%$ in (U)BM-Macs and $59.7 \pm 26.1 \%$ in (LPS+IFN $\gamma$ )BM-Macs (data not shown). These data suggests that PE is the preferred substrate of Pla2g5 in (IL-4)BM-Macs and that the low expression level of Pla2g5 in (U)BM-Macs and (LPS+IFN $\gamma$ )BM-Macs is sufficient to mobilize PE.

To understand whether Pla2g5 was active on selective PE or PC molecules, we analyzed PE and PC species in Pla2g5-null BM-Macs compared to WT BM-Macs. PE 36:1 (18:0, 18:1), PE 36:2 (18:0, 18:2), and PE 38:4 (18:0, 20:4) were increased in BM-Macs lacking Pla2g5 independently of the activation state. PE 34:1(16:0; 18:1), PE 34:2 (16:0,18:2), and PE $38: 5$ (16:0, 22:5; 18:1, and 20:4) were significantly increased in Pla2g5-null (IL-4)BM-Macs while PE 34:1 (16:0; 18:1) was increased in Pla2g5-null (LPS+IFN $\gamma$ )BM-Macs, compared to their respective controls (Figure 2c). In the PC group, PC 30:2 and PC 36:2 were increased in Pla2g5-null (U)BM-Macs compared to WT (U)BM-Macs (Figure 2d), while PC 34:1 and PC 36:2 were increased in Pla2g5-null (LPS+IFN $\gamma$ )BM-Macs compared to relative controls. These data suggest that Pla2g5 preferentially metabolized PE molecules in both (IL-4)BM-Macs and (LPS+IFN $\gamma$ )BM-Macs and that its activity on PC is restricted to (LPS+IFN $\gamma$ )BM-Macs. 
(a)

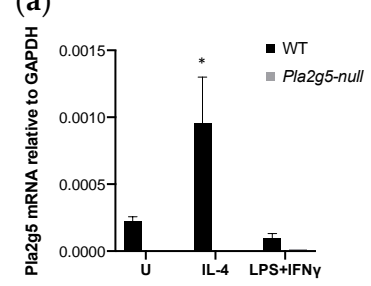

(c) (b)

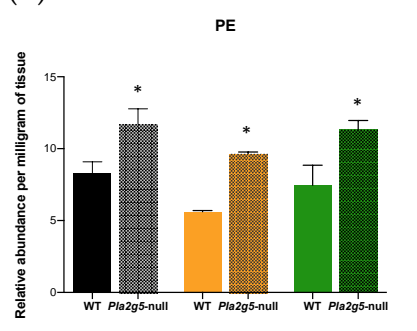

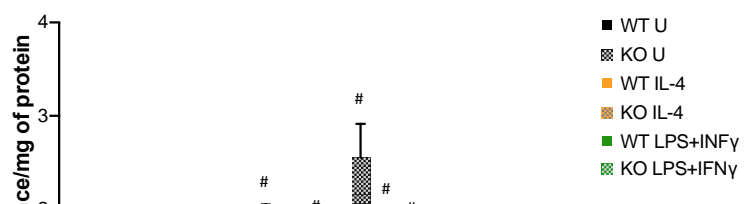

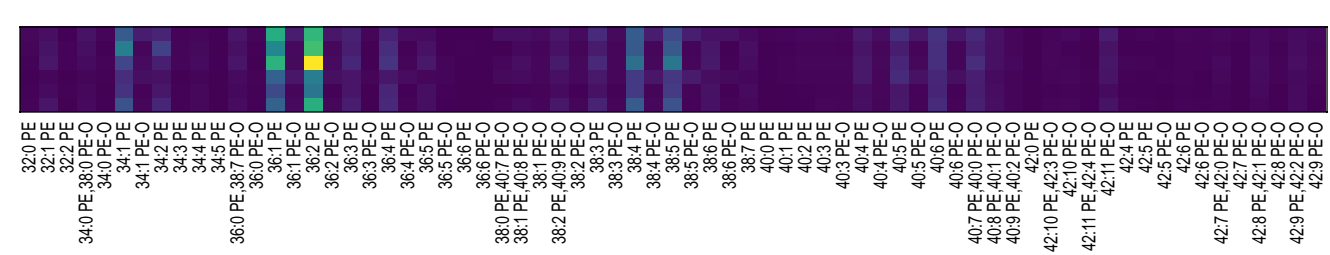

(d)

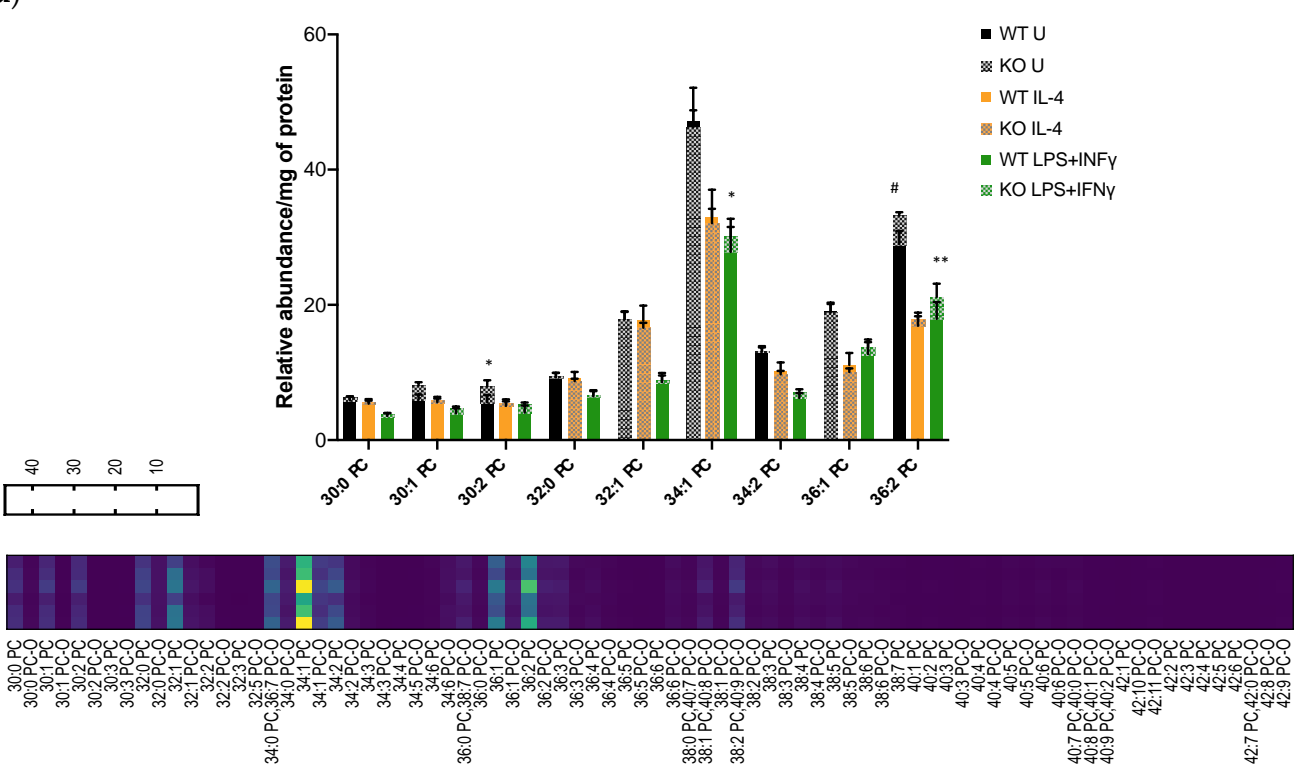

Figure 2. PE and PC molecules from WT and Group V phospholipase $A_{2}$ (Pla2g5)-null BM-Macs determined by LC-MS. Expression of Pla2g5 mRNA relative to Glyceraldehyde-3-Phosphate Dehydrogenase (GAPDH) measured by qPCR in WT (black bars) or Pla2g5-null BM-Macs (grey bars), Unstimulated (U) or stimulated with IL-4 or LPS+IFN $\gamma$ (a). BM-Macs isolated from WT (solid bars) or Pla2g5-null (dotted bars) mice were Unstimulated (U) or treated with IL-4 or LPS+IFN $\gamma$ for $24 \mathrm{~h}$ and (b) total PC and PE, (c) PE, or (d) PC molecules are reported. The data are shown as a heatmap of mean or graph of mean and standard error of three independent determinations. ${ }^{*} p<0.0001,{ }^{* *} p<0.005,{ }^{*} p<0.05$ by two-way ANOVA with Sidak's or Tukey's correction for multiple comparisons. 


\subsection{Lysophospholipid and Fatty Acid Generation in Activated BM-Macs}

To further investigate the changes in bioactive lipids during macrophage activation, we analyzed LysoPLs by LC-MS. A heat map of LysoPLs generated in BM-Macs showed that compared to unstimulated WT BM-Macs, LysoPC and Lysophosphatidylethanolamine (LysoPE) are substantially reduced following activation with either IL-4 or LPS+IFN $\gamma$ (Supplemental Figure S1). This is likely due to LysoPL being rapidly metabolized or re-acylated into membrane phospholipids [41]. Furthermore, there was no significant difference between WT and Pla2g5-null BM-Macs in either LysoPE or LysoPC molecules in any stimulation (Supplemental Figure S1).

FAs are bioactive lipids and the second product of PLA 2 activity on membrane phospholipids. We analyzed 33 FAs by GC-MS [42]. WT BM-Macs showed that FAs generated in (LPS+IFN $\gamma$ )BM-Macs and (IL-4)BM-Macs were reduced compared to (U)BM-Macs (data not shown), likely because they are being metabolized to their final products, eicosanoids. However, to understand whether Pla2g5 differentially contributes to FAs generated by activated macrophages, we compared FAs produced by WT BM-Macs and Pla2g5-null BM-Macs activated by IL-4 or LPS+IFN $\gamma$ (Figure $3 \mathrm{a}, \mathrm{b}$ ). There was a trend toward reduction in LA (18:2) in Pla2g5-null (IL-4)BM-Macs compared to WT (IL-4)BM-Macs (Figure 3a). However, myristic acid (MA; 14:0) was significantly higher in Pla2g5-null (IL-4)BM-Macs compared to WT (IL-4)BM-Macs. Instead, compared to WT (LPS+IFN $\gamma$ )BM-Macs, Pla2g5null (LPS+IFN $\gamma$ )BM-Macs had a significant reduction palmitic acid (PA; 16:0), and trends toward a reduction in AA (20:4) (Figure 3b).

(a)

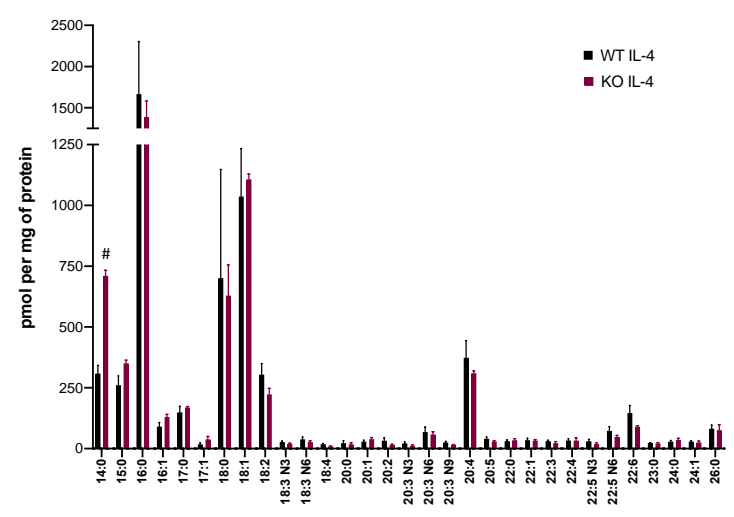

(b)

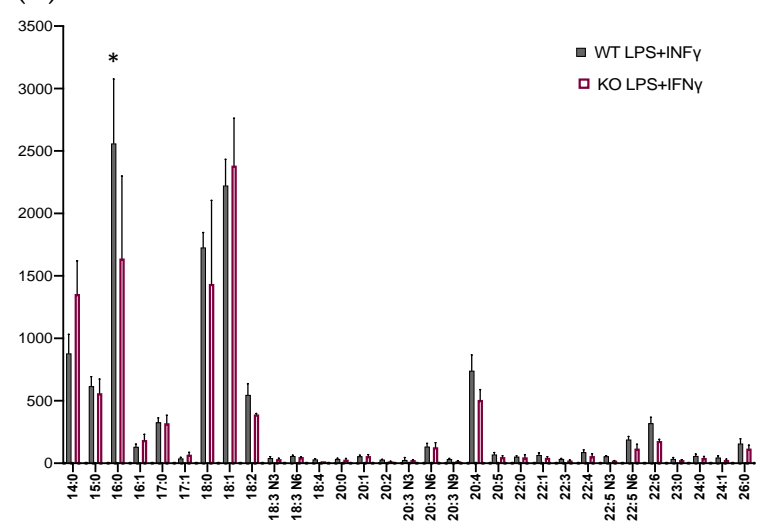

Figure 3. FAs release by activated WT and Pla2g5-null BM-Macs. BM-Macs isolated from WT or Pla2g5-null mice were Unstimulated (U) or treated with IL-4 (a) or LPS+IFN $\gamma(\mathbf{b})$ for $24 \mathrm{~h}$. The production of FAs measured by gas chromatography coupled to mass spectrometry (GC-MS) in WT and Pla2g5-null BM-Macrophages. Data are from three independent experiments. Two Way ANOVA followed by Fisher's LSD post-test. ${ }^{*} p<0.005,{ }^{*} p<0.01$.

\subsection{Differential Eicosanoid Generation in Bone Marrow-Derived Macrophages Activated by IL-4} or $L P S+I F N \gamma$

Because LysoPLs and FAs were reduced in activated BM-Macs compared to unstimulated BM-Macs, we reasoned that eicosanoid could be increased. To verify the effects of IL-4 and LPS+IFN $\gamma$ on the eicosanoids generated in BM-Macs, we performed an unbiased lipid profile by LC-MS/MS. We detected 32 of the 154 analyzed lipids. The eicosanoids produced by WT BM-Macs unstimulated and following IL-4 and LPS+IFN $\gamma$ activation originated from AA (C20:4), Eicosapentaenoic acid (EPA, 20:5), Dihomo- $\gamma$ linolenic acid (DGLA, 20:3), linoleic acid (LA, 18:2), Docosahexaenoic acid (DHA, 22:6), and Adrenic acid (AdA, 22:4) (Figure 4). WT unstimulated BM-Macs produced AA-derived metabolites generated through the three major enzymatic pathways COX, LOX, CYP, and nonenzymatically (n.e.). $\mathrm{PGD}_{2}$, Thromboxane $\mathrm{B}_{2}\left(\mathrm{TxB}_{2}\right), 12$-Hydroxy-eicosatetraenoic acid (12-HETE), 20CooH AA, 12-hydroxy-heptadecatrienoic acid (12-HHTrE), 13,14-dihydro- 
15-keto prostaglandin $\mathrm{D}_{2}$ (dhk $\left.\mathrm{PGD}_{2}\right)$, and Prostaglandin F metabolite (PGFM) were the most abundant (Figure 4). Compared to WT (U)BM-Macs, both (IL-4) and (LPS+IFN $\gamma$ )BMMacs had a significant increase in the production of the COX metabolites PGE 2 and $\mathrm{PGD}_{2}$. Instead, compared to WT (U)BM-Macs, in (LPS+IFN $\gamma$ )BM-Macs, there were increased amounts of $\mathrm{TxB}_{2}, \mathrm{PGA}_{2}, 12-\mathrm{HHTrE}$ (COX metabolites), 11-HETE (non-enzymatic product), and 12-HETE (LOX product). Furthermore, in (LPS+IFN $\gamma$ )BM-Macs, there was a trend in increasing 13-hydroxy-docosahexaenoic acid (13-HDoHE), 14-HDoHE, and dihomo- $\mathrm{PGF}_{2} \alpha$. Also, 20CooH AA, a metabolic product of CYP-generated 20-HETE, was significantly increased in (IL-4)BM-Macs compared to (U)BM-Macs. These data suggest that while LPS+IFN $\gamma$ robustly activates COX and LOX pathways, IL-4 activation of BM-Macs produces selective COX metabolites while also sustaining CYP metabolism as indicated by the increase in $20 \mathrm{CooH}$ AA.

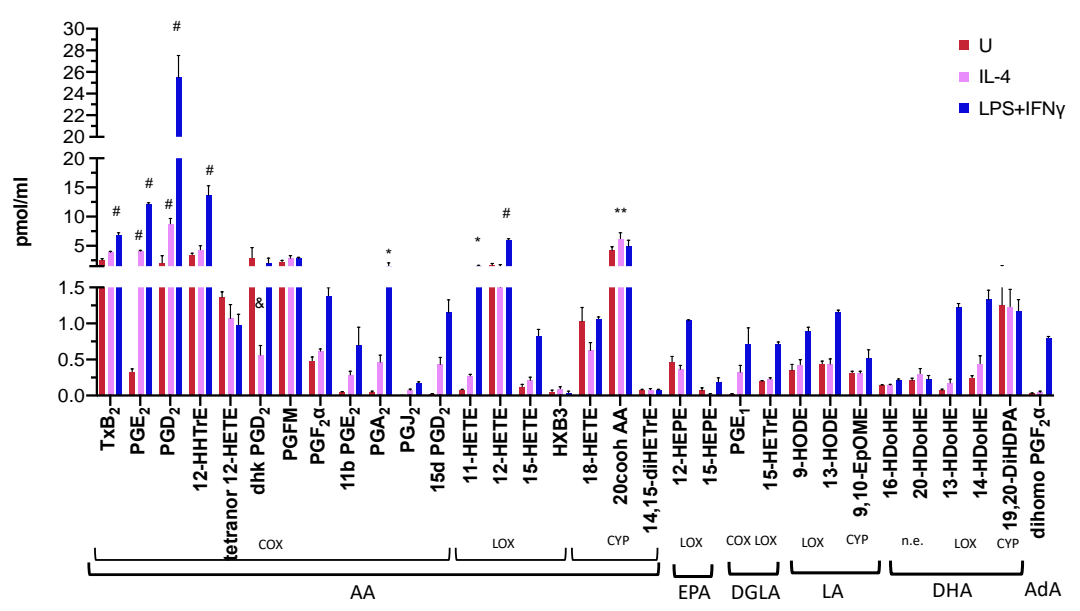

Figure 4. Eicosanoids produced by activated WT BM-Macs. Analysis by LC-MS/MS of cell-free supernatants obtained from WT BM-Macs unstimulated (U) and stimulated for $24 \mathrm{~h}$ with IL-4 or LPS+IFN $\gamma$. Shown is mean and standard error of eicosanoids produced by WT BM-Macs unstimulated (U, Purple bars) or activated with IL-4 (Red bars) or LPS+IFN $\gamma$ (Blue bars). Eicosanoids were identified based on matching chromatographic retention times (RTs), fragmentation patterns, and six characteristic and diagnostic ions. Cyclooxygenase (Cox), Lipoxygenase (LOX) Cytochrome P450 $(C Y P)$, non-enzymatically (n.e.), Thromboxane $\mathrm{B}_{2}\left(\mathrm{TxB}_{2}\right)$, Prostaglandin $\mathrm{E}_{2}\left(\mathrm{PGE}_{2}\right)$, prostaglandin $\mathrm{D}_{2}$ $\left(\mathrm{PGD}_{2}\right), 13$,14-dihydro-15-keto prostaglandin $\mathrm{D}_{2}$ (dhk $\left.\mathrm{PGD}_{2}\right), 20$-Carboxy-arachidonic acid (20CooH AA), 12-Hydroxyheptadecatrenoic acid (12-HHTrE), Prostaglandin F metabolite (PGFM), Hepoxilin B3 (HXB3), HODE (Hydroxy-octadecadienoic acid), EpHOME (epoxy-octadecenoic acid), HETrE (hydroxy-eicosatrienoic acid), HDoHE (hydroxy-docosahexaenoic acid), DiHDPA (dihydroxydocosapentaenoic acid), DiHETrE (dihydroxy-eicosatrienoic acid), HEPE (Hydroxy-eicosapentaenoic acid), HETE (Hydroxy-eicosatetraenoic acid), HPETE (Hydroperoxy-eicosatetraenoic acid), arachidonic acid (AA), LA (linoleic acid), DGLA (Dihomo-gamma linolenic acid) EPA (eicosapentaenoic acid), DHA (docosahexaenoic acid), AdA (Adrenic acid). ${ }^{\#} p<0.0001,{ }^{* *} p<0.001{ }^{*} p<0.05$ by two-way ANOVA with Dunnett's correction for multiple comparisons of three independent determinations.

\subsection{Pla2g5 Contributes to Selective Eicosanoid Generation in Unstimulated And Activated Macrophages}

To better understand the contribution of Pla2g5 to eicosanoid generation during macrophage polarization, we compared eicosanoid generation in WT BM-Macs and Pla2g5-null (U)BM-Macs and (IL-4) or (LPS+IFN $\gamma$ )BM-Macs (Figure 5). Compared to WT (U)BM-Macs, in Pla2g5-null (U)BM-Macs there was a reduction in $\mathrm{PGD}_{2}$, and dhk $\mathrm{PGD}_{2}$ (Figure 5b,c upper panels). Furthermore, compared to WT (IL-4)BM-Macs, in Pla2g5null (IL-4)BM-Macs, there was a significant reduction of $\mathrm{PGE}_{2}, \mathrm{PGD}_{2}$, and 20CooH AA (Figure 5b,c middle panels), the three metabolites that were significantly induced by IL-4 in WT BM-Macs. Stimulation of macrophages with LPS+IFN $\gamma$ revealed that Pla2g5-null 
(LPS+IFN $\gamma$ )BM-Macs have a significant reduction in $\mathrm{PGE}_{2}, \mathrm{PGD}_{2}$, and 12-HHTrE, compared to WT (LPS+IFN $\gamma$ )BM-Macs (Figure $5 b$,c lower panels). Unexpectedly, the absence of Pla2g5 in BM-Macs resulted in an increase of selected lipids: in unstimulated and in IL-4 activated BM-Macs lacking Pla2g5, PGFM was increased compared to equally treated WT BM-Macs (Figure 5b), while in (LPS+IFN $\gamma$ )BM-Macs lacking Pla2g5, 20CooH AA was increased compared to equally stimulated WT BM-Macs, likely as a result of reduced metabolism through the COX and LOX pathways. These data suggest that Pla2g5 is involved in the generation of selected metabolites of the COX pathway (IL-4)BM-Macs and metabolites of the COX and LOX pathways in (LPS+IFN $\gamma$ )BM-Macs, while CYP-induced production of $20 \mathrm{CooH}$ AA seemed to be associated with Pla2g 5 function in IL-4 activated macrophages. Cysteinyl-leukotrienes (Cys-LTs) were not detected in any conditions in either WT or Pla2g5-null BM-Macs.

(a)

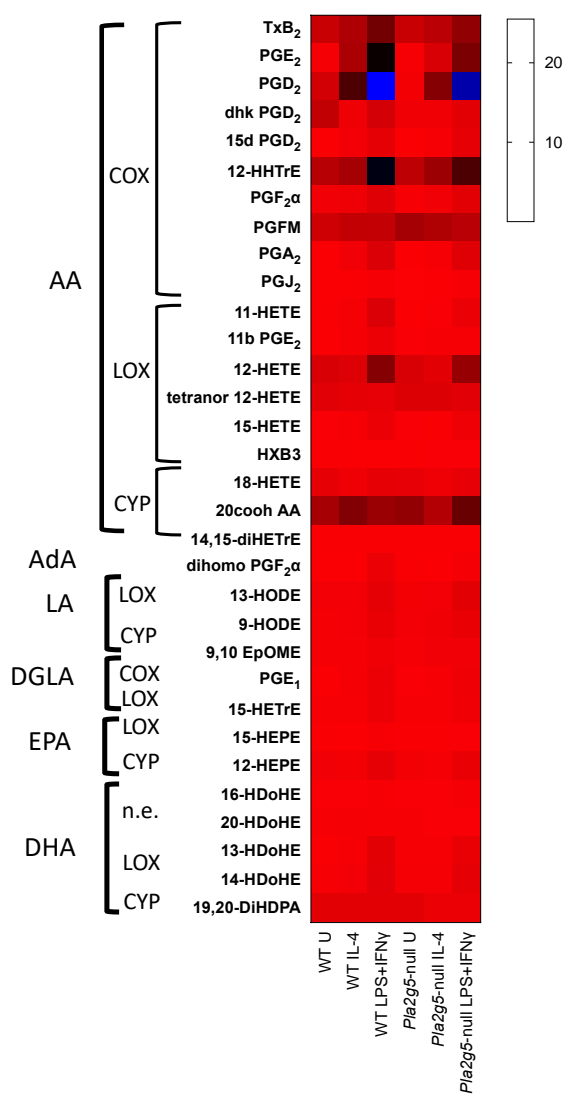

(b)

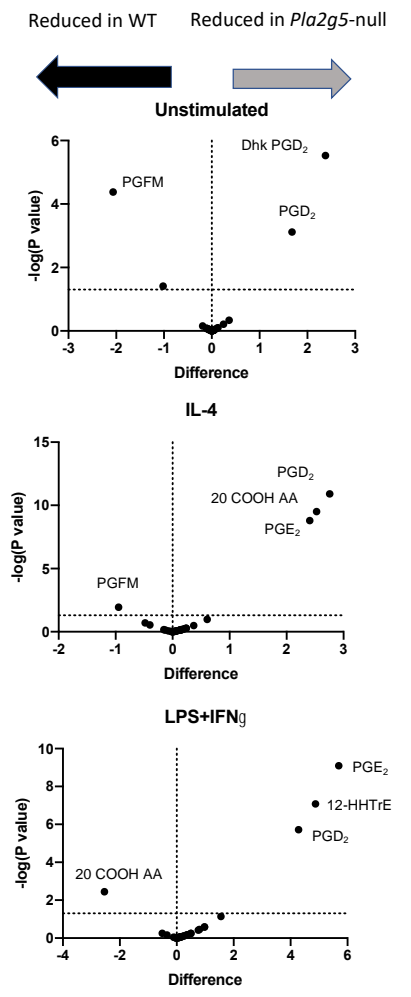

(c)
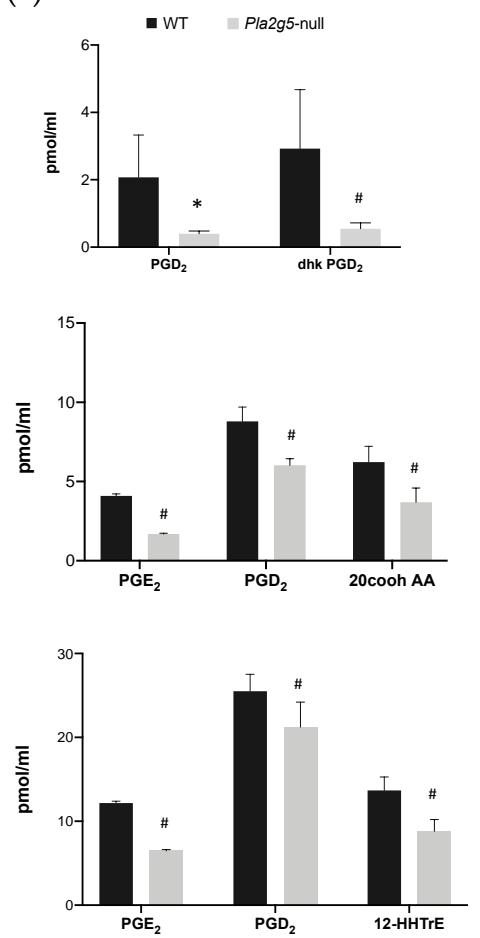

(d)

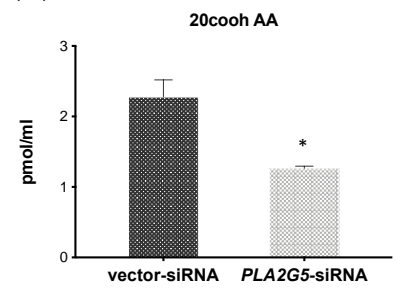

Figure 5. Contribution of Pla2g5 to eicosanoids produced by activated Macs. Analysis by LC-MS/MS of cell-free supernatants obtained from (a-c) WT and Pla2g5-null BM-Macs unstimulated (U) and stimulated for $24 \mathrm{~h}$ with IL-4 or LPS+IFN $\gamma$ or (d) $20 \mathrm{CooH}$ AA measured in the supernatants collected from vector- and PLA2G5-siRNA transfected human monocytederived macrophages (h-Macs) stimulated with IL-4. Shown are (a) heatmap (b) volcano plots of mean values (c,d) graphs of mean and standard error of eicosanoids produced. ${ }^{\#} p<0.0001,{ }^{*} p<0.05$ by two-way ANOVA with Sidak's (c) correction for multiple comparisons or $t$-Test (d) of three independent determinations.

To ascertain the contribution of human group V PLA 2 (PLA2G5) to eicosanoid generation in human monocyte-derived macrophages (h-Macs) activated by IL-4, we analyzed the lipidomic data set previously generated that demonstrated reduced $\mathrm{PGE}_{2}$ generation in the 
absence of PLA2G5 [20]. When compared with vector-treated (IL-4)h-Macs, PLA2G5-siRNAtreated (IL-4)h-Macs showed significant reduction of 20CooH AA ( $p=0.014$ ) (Figure 5d). Thus, Pla2g5 supports 20CooH AA production in mouse BM-Macs and h-Macs activated by IL-4.

\section{Discussion}

The study of macrophage activation has received increasing attention because of its potential implications in the development and treatment of multiple diseases. Macrophage activation is exemplified by the polarization of macrophages with IL-4 or LPS+IFN $\gamma$, each leading to differential gene expression, metabolism, cytokine, and chemokine production [13]. Although PLA 2 -generated bioactive lipids, which include FAs, PUFA-derived eicosanoids, and LysoPLs are central to many critical macrophage functions, they have not been extensively studied concerning macrophage activation and functions. Because Pla2g5 is expressed in macrophages and induced by IL-4, it is an attractive target to understand the contribution of bioactive lipids to macrophage polarization and functions. Here we performed a comprehensive analysis of PL, LysoPLs, FAs, and eicosanoids produced by BM-Macs under polarizing conditions, namely LPS+IFN $\gamma$ and IL-4 (Figure 6).

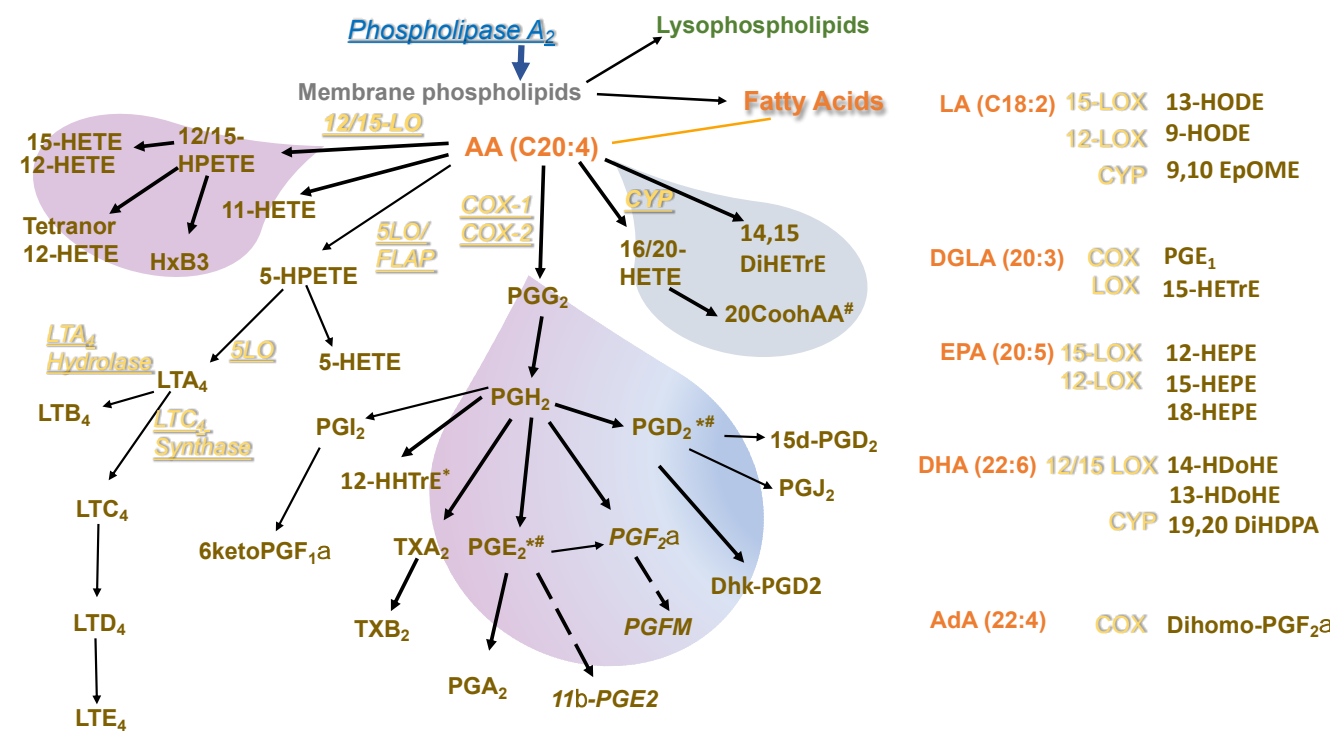

Figure 6. Flow-chart of bioactive lipids produced in activated BM-Macs and contribution of Pla2g5. Phospholipase $\mathrm{A}_{2}$ hydrolysis of membrane glycerophospholipids generates lysophospholipids, and free fatty acids including polyunsaturated fatty acids (PUFAs) which are then metabolized to eicosanoids through 3 enzymatic pathways: COX, LOX, and monooxygenases like CYP. Depicted in yellow are the enzymes; in brown the metabolites; and in orange are the fatty acids. The purple bubble depicts eicosanoids generate mainly through activation by LPS+IFN $\gamma$ in blue those generated mainly through IL-4 activation, and in purple-blue are those in common. Metabolites reduced in Pla2g5-null (LPS+IFN $\gamma$ )BM-Macs $\left(^{*}\right)$ or (IL-4)BM-Macs (\#). FLAP (5-lipoxygenase-activating protein).

Analysis of phospholipids in activated BM-Macs showed that PC and PE in BM-Macs are significantly reduced respectively in (LPS+IFN $\gamma$ )BM-Macs and (IL-4)BM-Macs. Major species including 34:1 PC and 36:2 PE were metabolized in both M1 (LPS+IFN $\gamma$ ) and M2 (IL-4) macrophages, which underscores the importance of lipid metabolism in macrophage activation. LPS+IFN $\gamma$ was more effective than IL-4 in reducing saturated PC species, including PC 30:0 and PC 32:0. These data are in line with reports in RAW264.7 mouse cell line and human monocyte-macrophages $[39,43]$, although the overall composition of membrane phospholipids in RAW264.7 showed a robust content of PA and PI at baseline, while in human monocyte-derived macrophages PS, PI, and PG contributed to PL composition and changes after activation [44]. Furthermore, IL-4 was more effective on PE metabolites 
than LPS+IFN $\gamma$, while both LPS+IFN $\gamma$ and IL-4 metabolized PE 38:4 PE and PE 38:5, two molecules that generate AA (20:4) by the action of PLA 2 s.

Macrophage functions are regulated by several $\mathrm{PLA}_{2} \mathrm{~s}$, including Pla2g5, Pla2g4a, Pla2g10, and Pla2g2d which may contribute to PL remodeling during activation [26,43,45]. Notably, Pla2g 5 mRNA is induced in macrophages by IL-4 but not LPS+IFN $\gamma[20,32,33]$. Indeed, Pla2g5-null BM-Macs had a significant increase in several PE molecules in (IL-4)BMMacs. During LPS+IFN $\gamma$ activation, Pla2g5-null BM-Macs had an increase only in PC 34:1, PC 36:2, and few PE molecules increased during IL-4 activation. Pla2g5 protein is expressed in resting macrophages and translocates following stimulation with pathogens [28]. The effects of Pla2g5 activity in (LPS+IFN $\gamma$ )BM-Macs are likely due to direct action of preexistent Pla2g5 on membrane PLs or through activation of Pla2g4a, constitutively expressed by macrophages [28] or other PLAs expressed in BM-Macs.

The analysis of LysoPLs did not show increased production of any LysoPLs in activated BM-Macs or a reduction in BM-Macs lacking Pla2g5. In our experiments, IL-4 did not increase the amount of LysoPL molecules in WT BM-Macs. LysoPLs could likely be re-acetylated during activation [46]. Alternatively, Pla2g5 could exert its functions on membrane lipids earlier than $24 \mathrm{~h}$, which is the time point used for macrophage activation [6]. However, it has been reported that macrophages derived from peripheral blood mononuclear cells and activated by IL-4 have reduced LysoPE but not LysoPC when depleted of PLA2G5 by siRNA and activated by IL-4 [33]. Our results also show a preference for Pla2g5 to target PE rather than PC during IL-4 activation of BM-Macs, but we did not detect a reduction of LysoPE molecules in Pla2g5-null BM-Macs. Differences in the type of macrophages and depletion of Pla2g5 may account for the discrepancies.

Given our previous data showing that LA and OA generated from macrophages induce pulmonary inflammation [34], we would have expected a decrease at least in selected PUFAs and MUFAs in BM-Macs lacking Pla2g5, particularly in IL-4 activation. Instead, in WT BM-Macs, despite the reduction in PC and PE species containing PUFAs and MUFAs, we could not detect an increase in FAs, making it difficult to detect a decrease in FAs in Pla2g5-null BM-Macs. However, FAs can serve as second messengers by binding to cognate receptors, they can be metabolized to supply energy to the cell, re-acylated into the membrane, or serve as substrate to generate eicosanoids [11,12,14,46,47]. Therefore, in cells activated in vitro, FAs are likely heavily used. However, our data showed that PA, the most abundant FA produced in either IL-4 or LPS+IFN $\gamma$ activation, is reduced in Pla2g5-null (LPS+IFN $\gamma$ )BM-Macs compared to equally treated WT BM-Macs. These results agree with the release of PA by Pla2g5 from other cell types during type 1 inflammation [48,49]. Surprisingly, (IL-4)BM-Macs lacking Pla2g5 had a significant increase in MA (14:0) compared to WT (IL-4)BM-Macs. As MA can be incorporated into a protein with consequences on signal transduction and AA metabolism, future studies await to ascertain the relevance of Pla2g5-generated MA in macrophage functions.

The reduction of PE 38:4 and 38:5 in Pla2g5-null BM-Macs suggests that, although the analysis of FAs does not support a contribution of Pla2g5 to the generation of AA or other PUFAs, it is likely that eicosanoid generation requires Pla2g5. In macrophages, prostanoids are abundantly produced following TLR-4 stimulation [50]. Furthermore, LPS stimulation increases eicosanoid generation by increasing $\mathrm{CPLA}_{2} \alpha$ activation and COX-2 expression [51-53]. Our data show that $\mathrm{PGD}_{2}$ was the most abundant eicosanoid produced by (U)BM-Macs and (LPS+IFN $\gamma$ )BM-Macs, as reported for RAW264.7 cells [53]. Furthermore, the absence of Pla2g5 significantly reduced $\mathrm{PGE}_{2}$ and $\mathrm{PGD}_{2}$ in IL-4 and (LPS+IFN $\gamma$ )BM-Macs, although the effect of LPS+IFN $\gamma$ was more robust. However, in (LPS+IFN $\gamma$ )BM-Macs, there was a reduction in 12-HHTrE, an eicosanoid reportedly produced by LPS activated macrophages [54]. These data suggest that the overarching effect of Pla2g5-generated eicosanoids during LPS+IFN $\gamma$ or IL-4 activation depends, in the former, on the combined action of at least $\mathrm{PGD}_{2}, \mathrm{PGE}_{2}$, and 12-HHTrE, in the latter on $\mathrm{PGD}_{2}$, $\mathrm{PGE}_{2}$, and 20CooH AA. Indeed, 20CooH AA was significantly induced (IL-4)BM-Macs and reduced in Pla2g5-null (IL-4)BM-Macs. 20 CooH AA is produced from 20-HETE, a 
product of CYP $\omega$-oxidation. It is a vasoactive metabolite and activator of PPAR $\gamma$ and PPAR $\alpha$ and, therefore, could play a role in Pla2g5-mediated IL-4-induced activation of macrophages [55]. These data indicate that compared with LPS+IFN $\gamma$, IL-4 stimulation of BM-Macs results in a weaker COX induction while also activating lipid $\omega$-oxidation, at least partially. The fact that $20 \mathrm{CooH}$ AA is increased in Pla2g5-null (LPS+IFN $\gamma$ )BM-Macs underscores the importance of Pla2g5 in the balance between lipid metabolites generated during LPS+IFN $\gamma$ activation of BM-Macs (COX and 12-15LOX derived) and IL-4 activation (COX and CYP derived). The importance of $20 \mathrm{CooH}$ AA in macrophages expressing Pla2g5 is also supported by our data showing that (IL-4)h-Macs lacking PLA2G5 have reduced production of $20 \mathrm{CooH}$ AA. In another report, human monocyte-derived macrophages activated with IL-4 and deprived of PLA2G5, did not show any eicosanoid reduction. Our protocol involves monocytes' isolation by negative selection and culture of the cells in GM-CSF for 10 days to achieve high TGM2 expression [7] and PLA2G5 expression [20]. Therefore, the discrepancies may depend on protocols adopted. However, the relevance of $20 \mathrm{CooH}$ AA in any macrophage functions related to Pla2g5 needs to be validated likely by in vivo experiments using mouse models.

Lipoxygenase derived lipids, including Cys-LTs, are potent proinflammatory mediators which are generated by dendritic cells, mast cells, macrophages and Th2 cells. In BM-Macs, we could not detect Cys-LTs (data not shown), likely because the delayed stimulation of $24 \mathrm{~h}$ necessary for macrophage polarization in vitro prevents the detection of Cys-LTs. Our data are in line with reports in RAW264.7 cells in which stimulation with Kdo2-Lipid A, a lipopolysaccharide, induces the COX pathway and downregulates the 5-LOX pathway [56]. Furthermore, it cannot be excluded that exogenous Pla2g5 may induce CysLTs generation [57].

The profile of lipids of BM-Macs in one-time point and in Pla2g5-null BM-Macs provides a snapshot of the function of a lipid-packed, heterogeneous cell, like macrophages. It does not consider other $\mathrm{PLA}_{2} \mathrm{~s}$ expressed in macrophages, including Pla2g4a, Pla2g2d, and Pla2g10, or other sources of exogenous Pla2g5. However, an imbalance between pro and anti-inflammatory lipids could account for the different role of Pla2g5 in the pathogenesis of several pathologies. Additionally, the expression of Pla2g5 in hematopoietic vs. non-hematopoietic cells could also determine the function of Pla2g5 in different diseases $[25,26]$. A recent study showed that in endothelial cells, the expression of Pla2g5 mRNA is higher than other PLA $_{2} \mathrm{~S}$ (Pla2g1b, 2a, 2d, 2e, 2f, and 10) then its expression is reduced by Angiotensin II stimulation while Pla2g5 protein is still present on the cell surface, likely linked to proteoglycans [49]. On the other hand, in resting macrophages, Pla2g 5 mRNA is almost undetectable and is induced by IL-4, while the protein, located intracellularly in resting macrophages, is secreted upon activation [20,29]. As macrophages are hematopoietic derived cells while endothelial cells are derived from mesodermal cells, it is likely that subcellular location and cell ontogeny could also predict Pla2g5 pro or anti-inflammatory functions.

\section{Conclusions}

The combined proinflammatory or anti-inflammatory properties of the lipids produced by M1 (LPS+IFN $\gamma$ ) or M2 (IL-4) activated macrophages may contribute to the functions of macrophages in different diseases. The identification of a potential lipid signature in M1 and M2 macrophages could identify new pathways critical for the development, persistence, or reduction of inflammation. Some of these functions may rely on the presence or absence of Pla2g5 in macrophages.

Supplementary Materials: The following are available online at https:/ / www.mdpi.com/2218-273 X/11/1/25/s1, Figure S1: LysoPL produced by activates BM-Macs.

Author Contributions: Conceptualization, B.B.; methodology, M.K., M.Y., and S.K.S.; validation, M.Y., M.K., and B.B.; formal analysis, M.K., M.Y., and S.K.S.; investigation, M.K., S.K.S., and M.Y.; resources, B.B.; data curation, M.K., S.K.S., and M.Y.; writing-original draft preparation, B.B.; 
writing—review and editing, M.K., M.Y., S.K.S., and B.B.; supervision, B.B.; funding acquisition, B.B. All authors have read and agreed to the published version of the manuscript.

Funding: This research was funded by National Heart, Lung, and Blood Institute, grant number 113071.

Conflicts of Interest: The authors declare no conflict of interest.

\section{References}

1. Gordon, S.; Pluddemann, A. The mononuclear phagocytic system. Generation of diversity. Front Immunol. 2019, 10, 1893. [CrossRef]

2. Locati, M.; Curtale, G.; Mantovani, A. Diversity, mechanisms, and significance of macrophage plasticity. Annu. Rev. Pathol. 2020, 15, 123-147. [CrossRef] [PubMed]

3. Ying, W.; Fu, W.; Lee, Y.S.; Olefsky, J.M. The role of macrophages in obesity-associated islet inflammation and beta-cell abnormalities. Nat. Rev. Endocrinol. 2020, 16, 81-90. [CrossRef] [PubMed]

4. Gosselin, D.; Link, V.M.; Romanoski, C.E.; Fonseca, G.J.; Eichenfield, D.Z.; Spann, N.J.; Stender, J.D.; Chun, H.B.; Garner, H.; Geissmann, F.; et al. Environment drives selection and function of enhancers controlling tissue-specific macrophage identities. Cell 2014, 159, 1327-1340. [CrossRef]

5. Ginhoux, F.; Schultze, J.L.; Murray, P.J.; Ochando, J.; Biswas, S.K. New insights into the multidimensional concept of macrophage ontogeny, activation and function. Nat. Immunol. 2016, 17, 34-40. [CrossRef] [PubMed]

6. Martinez, F.O.; Gordon, S. The M1 and M2 paradigm of macrophage activation: Time for reassessment. F1000Prime Rep. 2014, 6. [CrossRef]

7. Martinez, F.O.; Helming, L.; Milde, R.; Varin, A.; Melgert, B.N.; Draijer, C.; Thomas, B.; Fabbri, M.; Crawshaw, A.; Ho, L.P.; et al. Genetic programs expressed in resting and IL-4 alternatively activated mouse and human macrophages: Similarities and differences. Blood 2013, 121, e57-e69. [CrossRef]

8. Gieseck, R.L., III; Wilson, M.S.; Wynn, T.A. Type 2 immunity in tissue repair and fibrosis. Nat. Rev. Immunol. 2018, 18, 62-76. [CrossRef]

9. Lackey, D.E.; Olefsky, J.M. Regulation of metabolism by the innate immune system. Nat. Rev. Endocrinol. 2016, 12, 15-28. [CrossRef]

10. Wang, F.; Zhang, S.; Jeon, R.; Vuckovic, I.; Jiang, X.; Lerman, A.; Folmes, C.D.; Dzeja, P.D.; Herrmann, J. Interferon gamma induces reversible metabolic reprogramming of M1 macrophages to sustain cell viability and pro-inflammatory activity. EBioMedicine 2018, 30, 303-316. [CrossRef]

11. Vats, D.; Mukundan, L.; Odegaard, J.I.; Zhang, L.; Smith, K.L.; Morel, C.R.; Wagner, R.A.; Greaves, D.R.; Murray, P.J.; Chawla, A Oxidative metabolism and PGC-1beta attenuate macrophage-mediated inflammation. Cell Metab. 2006, 4, 13-24. [CrossRef] [PubMed]

12. Ecker, J.; Liebisch, G.; Grandl, M.; Schmitz, G. Lower SCD expression in dendritic cells compared to macrophages leads to membrane lipids with less mono-unsaturated fatty acids. Immunobiology 2010, 215, 748-755. [CrossRef] [PubMed]

13. Jha, A.K.; Huang, S.C.; Sergushichev, A.; Lampropoulou, V.; Ivanova, Y.; Loginicheva, E.; Chmielewski, K.; Stewart, K.M.; Ashall, J.; Everts, B.; et al. Network integration of parallel metabolic and transcriptional data reveals metabolic modules that regulate macrophage polarization. Immunity 2015, 42, 419-430. [CrossRef] [PubMed]

14. Ecker, J.; Liebisch, G.; Englmaier, M.; Grandl, M.; Robenek, H.; Schmitz, G. Induction of fatty acid synthesis is a key requirement for phagocytic differentiation of human monocytes. Proc. Natl. Acad. Sci. USA 2010, 107, 7817-7822. [CrossRef]

15. Lukic, A.; Larssen, P.; Fauland, A.; Samuelsson, B.; Wheelock, C.E.; Gabrielsson, S.; Radmark, O. GM-CSF- and M-CSF-primed macrophages present similar resolving but distinct inflammatory lipid mediator signatures. FASEB J. 2017, 31, 4370-4381. [CrossRef]

16. Stein, M.; Keshav, S.; Harris, N.; Gordon, S. Interleukin 4 potently enhances murine macrophage mannose receptor activity: A marker of alternative immunologic macrophage activation. J. Exp. Med. 1992, 176, 287-292. [CrossRef]

17. Kanaoka, Y.; Austen, K.F. Roles of cysteinyl leukotrienes and their receptors in immune cell-related functions. Adv. Immunol. 2019, 142, 65-84. [CrossRef]

18. Samuchiwal, S.K.; Balestrieri, B.; Raff, H.; Boyce, J.A. Endogenous prostaglandin E2 amplifies IL-33 production by macrophages through an E prostanoid (EP)2/EP4-cAMP-EPAC-dependent pathway. J. Biol. Chem. 2017, 292, 8195-8206. [CrossRef]

19. Samuchiwal, S.K.; Boyce, J.A. Role of lipid mediators and control of lymphocyte responses in type 2 immunopathology. J. Allergy Clin. Immunol. 2018, 141, 1182-1190. [CrossRef]

20. Yamaguchi, M.; Zacharia, J.; Laidlaw, T.M.; Balestrieri, B. PLA2G5 regulates transglutaminase activity of human IL-4-activated M2 macrophages through PGE2 generation. J. Leukoc. Biol. 2016, 100, 131-141. [CrossRef]

21. Bystrom, J.; Wray, J.A.; Sugden, M.C.; Holness, M.J.; Swales, K.E.; Warner, T.D.; Edin, M.L.; Zeldin, D.C.; Gilroy, D.W.; Bishop-Bailey, D. Endogenous epoxygenases are modulators of monocyte/macrophage activity. PLoS ONE 2011, 6, e26591. [CrossRef] [PubMed]

22. Fang, X.; Dillon, J.S.; Hu, S.; Harmon, S.D.; Yao, J.; Anjaiah, S.; Falck, J.R.; Spector, A.A. 20-carboxy-arachidonic acid is a dual activator of peroxisome proliferator-activated receptors alpha and gamma. Prostaglandins Lipid Mediat. 2007, 82, 175-184. [CrossRef] [PubMed] 
23. Garcia, V.; Gilani, A.; Shkolnik, B.; Pandey, V.; Zhang, F.F.; Dakarapu, R.; Gandham, S.K.; Reddy, N.R.; Graves, J.P.; Gruzdev, A.; et al. 20-HETE signals through g-protein-coupled receptor GPR75 (Gq) to affect vascular function and trigger hypertension. Circ. Res. 2017, 120, 1776-1788. [CrossRef] [PubMed]

24. Huang, S.C.; Everts, B.; Ivanova, Y.; O’Sullivan, D.; Nascimento, M.; Smith, A.M.; Beatty, W.; Love-Gregory, L.; Lam, W.Y.; O'Neill, C.M.; et al. Cell-intrinsic lysosomal lipolysis is essential for alternative activation of macrophages. Nat. Immunol. 2014, 15, 846-855. [CrossRef] [PubMed]

25. Samuchiwal, S.K.; Balestrieri, B. Harmful and protective roles of group V phospholipase A2: Current perspectives and future directions. Biochim. Biophys. Acta Mol. Cell Biol. Lipids 2019, 1864, 819-826. [CrossRef]

26. Murakami, M.; Sato, H.; Taketomi, Y. Updating phospholipase A2 biology. Biomolecules 2020, 10, 1457. [CrossRef]

27. Balestrieri, B.; Hsu, V.W.; Gilbert, H.; Leslie, C.C.; Han, W.K.; Bonventre, J.V.; Arm, J.P. Group V secretory phospholipase A2 translocates to the phagosome after zymosan stimulation of mouse peritoneal macrophages and regulates phagocytosis. J. Biol. Chem. 2006, 281, 6691-6698. [CrossRef]

28. Ruiperez, V.; Astudillo, A.M.; Balboa, M.A.; Balsinde, J. Coordinate regulation of TLR-mediated arachidonic acid mobilization in macrophages by group IVA and group V phospholipase A2s. J. Immunol. 2009, 182, 3877-3883. [CrossRef]

29. Balestrieri, B.; Maekawa, A.; Xing, W.; Gelb, M.H.; Katz, H.R.; Arm, J.P. Group V secretory phospholipase A2 modulates phagosome maturation and regulates the innate immune response against Candida albicans. J. Immunol. 2009, 182, 4891-4898. [CrossRef]

30. Lapointe, S.; Brkovic, A.; Cloutier, I.; Tanguay, J.F.; Arm, J.P.; Sirois, M.G. Group V secreted phospholipase A2 contributes to LPS-induced leukocyte recruitment. J. Cell. Physiol. 2010, 224, 127-134. [CrossRef]

31. Munoz, N.M.; Meliton, A.Y.; Meliton, L.N.; Dudek, S.M.; Leff, A.R. Secretory group V phospholipase A2 regulates acute lung injury and neutrophilic inflammation caused by LPS in mice. Am. J. Physiol. Lung Cell Mol. Physiol. 2009, 296, L879-L887. [CrossRef] [PubMed]

32. Ohta, S.; Imamura, M.; Xing, W.; Boyce, J.A.; Balestrieri, B. Group V secretory phospholipase A2 is involved in macrophage activation and is sufficient for macrophage effector functions in allergic pulmonary inflammation. J. Immunol. 2013, 190, 5927-5938. [CrossRef] [PubMed]

33. Rubio, J.M.; Rodriguez, J.P.; Gil-de-Gomez, L.; Guijas, C.; Balboa, M.A.; Balsinde, J. Group V secreted phospholipase A2 is upregulated by IL-4 in human macrophages and mediates phagocytosis via hydrolysis of ethanolamine phospholipids. J. Immunol. 2015, 194, 3327-3339. [CrossRef] [PubMed]

34. Yamaguchi, M.; Samuchiwal, S.K.; Quehenberger, O.; Boyce, J.A.; Balestrieri, B. Macrophages regulate lung ILC2 activation via Pla2g5-dependent mechanisms. Mucosal. Immunol. 2017. [CrossRef]

35. Satake, Y.; Diaz, B.L.; Balestrieri, B.; Lam, B.K.; Kanaoka, Y.; Grusby, M.J.; Arm, J.P. Role of group V phospholipase A2 in zymosan-induced eicosanoid generation and vascular permeability revealed by targeted gene disruption. J. Biol. Chem. 2004, 279, 16488-16494. [CrossRef]

36. Xue, J.; Schmidt, S.V.; Sander, J.; Draffehn, A.; Krebs, W.; Quester, I.; de Nardo, D.; Gohel, T.D.; Emde, M.; Schmidleithner, L.; et al. Transcriptome-based network analysis reveals a spectrum model of human macrophage activation. Immunity 2014, 40, 274-288. [CrossRef]

37. Quehenberger, O.; Armando, A.M.; Brown, A.H.; Milne, S.B.; Myers, D.S.; Merrill, A.H.; Bandyopadhyay, S.; Jones, K.N.; Kelly, S.; Shaner, R.L.; et al. Lipidomics reveals a remarkable diversity of lipids in human plasma. J. Lipid Res. 2010, 51, 3299-3305. [CrossRef]

38. Wang, Y.; Armando, A.M.; Quehenberger, O.; Yan, C.; Dennis, E.A. Comprehensive ultra-performance liquid chromatographic separation and mass spectrometric analysis of eicosanoid metabolites in human samples. J. Chromatogr. A 2014, 1359, 60-69. [CrossRef]

39. Quehenberger, O.; Armando, A.; Dumlao, D.; Stephens, D.L.; Dennis, E.A. Lipidomics analysis of essential fatty acids in macrophages. Prostaglandins Leukot. Essent. Fat. Acids 2008, 79, 123-129. [CrossRef]

40. Murray, P.J.; Allen, J.E.; Biswas, S.K.; Fisher, E.A.; Gilroy, D.W.; Goerdt, S.; Gordon, S.; Hamilton, J.A.; Ivashkiv, L.B.; Lawrence, T.; et al. Macrophage activation and polarization: Nomenclature and experimental guidelines. Immunity 2014, 41, 14-20. [CrossRef]

41. Shindou, H.; Hishikawa, D.; Harayama, T.; Eto, M.; Shimizu, T. Generation of membrane diversity by lysophospholipid acyltransferases. J. Biochem. 2013, 154, 21-28. [CrossRef] [PubMed]

42. Quehenberger, O.; Armando, A.M.; Dennis, E.A. High sensitivity quantitative lipidomics analysis of fatty acids in biological samples by gas chromatography-mass spectrometry. Biochim. Biophys. Acta 2011, 1811, 648-656. [CrossRef] [PubMed]

43. Dennis, E.A.; Deems, R.A.; Harkewicz, R.; Quehenberger, O.; Brown, H.A.; Milne, S.B.; Myers, D.S.; Glass, C.K.; Hardiman, G.; Reichart, D.; et al. A mouse macrophage lipidome. J. Biol. Chem. 2010, 285, 39976-39985. [CrossRef] [PubMed]

44. Montenegro-Burke, J.R.; Sutton, J.A.; Rogers, L.M.; Milne, G.L.; McLean, J.A.; Aronoff, D.M. Lipid profiling of polarized human monocyte-derived macrophages. Prostaglandins Other Lipid Mediat. 2016, 127, 1-8. [CrossRef] [PubMed]

45. Nolin, J.D.; Lai, Y.; Ogden, H.L.; Manicone, A.M.; Murphy, R.C.; An, D.; Frevert, C.W.; Ghomashchi, F.; Naika, G.S.; Gelb, M.H.; et al. Secreted PLA2 group X orchestrates innate and adaptive immune responses to inhaled allergen. JCI Insight 2017, 2. [CrossRef] [PubMed]

46. Shindou, H.; Hishikawa, D.; Harayama, T.; Yuki, K.; Shimizu, T. Recent progress on acyl CoA: Lysophospholipid acyltransferase research. J. Lipid Res. 2009, 50, S46-S51. [CrossRef] 
47. Alvarez-Curto, E.; Milligan, G. Metabolism meets immunity: The role of free fatty acid receptors in the immune system. Biochem. Pharm. 2016, 114, 3-13. [CrossRef]

48. Sato, H.; Taketomi, Y.; Ushida, A.; Isogai, Y.; Kojima, T.; Hirabayashi, T.; Miki, Y.; Yamamoto, K.; Nishito, Y.; Kobayashi, T.; et al. The adipocyte-inducible secreted phospholipases PLA2G5 and PLA2G2E play distinct roles in obesity. Cell Metab. 2014, 20, 119-132. [CrossRef]

49. Watanabe, K.; Taketomi, Y.; Miki, Y.; Kugiyama, K.; Murakami, M. Group V secreted phospholipase A2 plays a protective role against aortic dissection. J. Biol. Chem. 2020, 295, 10092-10111. [CrossRef]

50. Norris, P.C.; Reichart, D.; Dumlao, D.S.; Glass, C.K.; Dennis, E.A. Specificity of eicosanoid production depends on the TLR-4stimulated macrophage phenotype. J. Leukoc. Biol. 2011, 90, 563-574. [CrossRef]

51. Qi, H.Y.; Shelhamer, J.H. Toll-like receptor 4 signaling regulates cytosolic phospholipase A2 activation and lipid generation in lipopolysaccharide-stimulated macrophages. J. Biol. Chem. 2005, 280, 38969-38975. [CrossRef] [PubMed]

52. Ueno, N.; Takegoshi, Y.; Kamei, D.; Kudo, I.; Murakami, M. Coupling between cyclooxygenases and terminal prostanoid synthases. Biochem. Biophys. Res. Commun. 2005, 338, 70-76. [CrossRef] [PubMed]

53. Buczynski, M.W.; Stephens, D.L.; Bowers-Gentry, R.C.; Grkovich, A.; Deems, R.A.; Dennis, E.A. TLR-4 and sustained calcium agonists synergistically produce eicosanoids independent of protein synthesis in RAW264. 7 cells. J. Biol. Chem. 2007, 282, 22834-22847. [CrossRef] [PubMed]

54. Fromel, T.; Kohlstedt, K.; Popp, R.; Yin, X.; Awwad, K.; Barbosa-Sicard, E.; Thomas, A.C.; Lieberz, R.; Mayr, M.; Fleming, I. Cytochrome P4502S1: A novel monocyte/macrophage fatty acid epoxygenase in human atherosclerotic plaques. Basic Res. Cardiol. 2013, 108, 319. [CrossRef]

55. Odegaard, J.I.; Ricardo-Gonzalez, R.R.; Goforth, M.H.; Morel, C.R.; Subramanian, V.; Mukundan, L.; Eagle, A.R.; Vats, D.; Brombacher, F.; Ferrante, A.W.; et al. Macrophage-specific PPARgamma controls alternative activation and improves insulin resistance. Nature 2007, 447, 1116-1120. [CrossRef]

56. Buczynski, M.W.; Dumlao, D.S.; Dennis, E.A. Thematic review series: Proteomics. An integrated omics analysis of eicosanoid biology. J. Lipid Res. 2009, 50, 1015-1038. [CrossRef]

57. Boilard, E.; Lai, Y.; Larabee, K.; Balestrieri, B.; Ghomashchi, F.; Fujioka, D.; Gobezie, R.; Coblyn, J.S.; Weinblatt, M.E.; Massarotti, E.M.; et al. A novel anti-inflammatory role for secretory phospholipase A2 in immune complex-mediated arthritis. EMBO Mol. Med. 2010, 2, 172-187. [CrossRef] 